https://www.journal-imab-bg.org

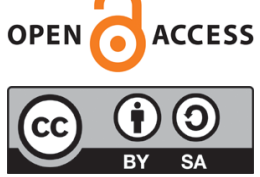

Original article

\title{
EFFECT OF HYDROTHERAPY ON CHRONIC PAIN IN THE LUMBAR REGION
}

\author{
Mariya Gramatikova, Stamenka Mitova, Nasko Valchev \\ Department of Kinesitherapy, Faculty of Public Health, Healthcare and Sports, \\ South-West University "Neofit Rilski” Blagoevgrad, Bulgaria..
}

\section{SUMMARY}

Purpose: To develop and study the effectiveness of methods and algorithms using a specialized magnetotherapy with underwater water-jet massage for chronic lumbar pain.

Material/Methods: 30 subjects from two experimental groups (EG-1 from 15 athletes and EG-2 from 15 non-athletes) were examined, all with chronic lumbar pain. Testing is performed - before and after one month of physiotherapy. The test battery includes: anthropometry (height, body weight); visual-analogue pain scale; Laseg test - for the neurodynamics of n.ischiadicus. Physiotherapy includes hydrotherapy, with a water temperature of $36^{\circ}-37^{\circ}$ and magnetotherapy with a duration of 30 - 35 min - treatment of the paravertebral muscle in the lumbar region, gluteus and lower limbs - dorsal and ventral. The procedures are applied 3 times a week for one month.

Results: Methods and algorithms using a specialized magnetotherapy with underwater water-jet massage for patients with chronic lumbar pain have been developed. Pain on the Visual-Ana$\log$ Scale of EG-1 athletes was studied - before physiotherapy (with hydrotherapy) $\bar{X}=4.93 \pm 1.39 \mathrm{~mm}, \mathrm{~V} \%=28.12 \%$, which is an indicator of severe pain in the lumbar region. After 30 days, physiotherapy was reduced to $\bar{X}=1.53 \pm 0.99 \mathrm{~mm}$, at V\% $=64.59 \%$. Its decrease is $31.03 \%, \mathrm{P}<0.01$. Pain before physiotherapy was found in EG-2 $\bar{X}=6.87 \pm 1.64 \mathrm{~mm}$, at V\% $=23.91 \%$. After physiotherapy, it is reduced to $\bar{X}=1.93 \pm 1.49 \mathrm{~mm}$, at $\mathrm{V} \%=76.89 \%, \mathrm{P}<0.01$. A study of the neurodynamics of n.ischiadicus, through the Laseg test, found that passive flexion in the hip joint of the healthy leg - before physiotherapy with EG-1 hydrotherapy was $\bar{X}=76.33 \pm 8.76^{\circ}$, at V\% $=$ $11.47 \%$. After hydrotherapy increased to $\bar{X}=86.33 \pm 5.51^{\circ}$, at $\mathrm{V} \%=6.37 \%$. Passive flexion in the hip joint of the injured leg before hydrotherapy was detected in EG-1. $\bar{X}=69.67 \pm 10.43^{\circ}$, which indicates its strong limit. Post-hydrotherapy $\bar{X}=80.33 \pm 10.08^{\circ}$, at $\mathrm{V} \%=12.55 \%$. $\mathrm{P}<0.0$. In EG-2, the passive flexion in the hip joint before hydrotherapy, the healthy leg was $\bar{X}=71.67 \pm 14.1^{\circ}, \mathrm{V} \%=$ $19.67 \%$. After hydrotherapy increased to $\bar{X}=81.53 \pm 8.37^{\circ}$. In V\% $=10.26 \%$. In the injured leg, passive flexion - before hydrotherapy was $\bar{X}=71.00 \pm 11.37^{\circ}$, after it $\bar{X}=82.07 \pm 7.70^{\circ}, \mathrm{V} \%=9.39 \%$. $\mathrm{P}<0.01$.

Conclusion: The proven technique and algorithms of hydrotherapy, with a specialized magnetotherapy with underwater water-jet massage, is effective for the recovery of persons with chronic lumbar pain. The technique reduces the neurological and pain symptoms and the restoration of n.ischiadicus.

Keywords: physiotherapy, neurodynamics, lumbar pain, hydrotherapy, magnetotherapy,

\section{INTRODUCTION:}

Chronic low back pain (CLBP) is a chronic pain syndrome in the lower back region, last 3 months. CLBP represents the second lead in the cause of disability worldwide, being major welfare and economic problem [1]. CLBP may be nociceptive or neuropathic or may incorporate both components. The presence of a neuropathic component is associated with the more intense pain of longer duration, and a higher prevalence of co-morbidities [2]. In sports training and competition, athletes suffer different severity of injuries, followed by a lengthy recovery process by physiotherapists. To maintain the athletic form of the athletes, it is important to speed up the recovery processes in the body and fully integrate them into the next stages of sports training [3].

This is mainly achieved through physiotherapy, including restorative massages, êinesiotape, hydrotherapy [4] and other means. The effect of water is multidirectional, by reducing edema, causing an effluent effect, increasing the range of motion of joints [5], activating regenerative processes, improving myo-articular laxity, relaxing spastic hypertonic muscles, improves the manifestation of strength and endurance [6] and dynamic joint stability [7]. Hydrotherapy is also suitable for non-sports, with other injuries of the musculoskeletal system, muscle weakness, limited mobility of traumatic joints, arthrosis, musculoskeletal deformities of the musculoskeletal system [8] and the like.

The complex positive effect of hydrotherapy on the musculoskeletal system causes an increase in the range of motion in the joints, increases the elasticity of soft tissues, relaxes spastic and toned muscles, influences effluent, pain suppressant, improves the manifestation of strength and endurance, improves dynamic joint stability [9, 10].

Hydrotherapy (with a tangentor) also has a mechanical effect, a massage effect associated with suppression, a proprioceptive effect in impaired proprioception; weak neuromuscular control, impaired neuromuscular synergism, impaired coordination and equilibrium, impaired dynamic joint stability and locomotor capacity [10], in which cases the restoration of dynamic proprioceptive reactivity is prioritized $[9,10]$.

Hydrotherapy has also been used as a cryo-effect [11] for the reduction of edema, pain and inflammatory response [12]. It affects the myo-articular tissues - tendons, tendons vagina, ligaments and bursa, muscles. In the presence of pain near the muscle, the reflex response of the muscle is a spasm, thus immobilizing the source of the pain [13]. 


\section{MATERIAL/METHODS:}

The studies were conducted at the Bachinovo "Research and Sports Recovery Center", at South-West University "Neofit Rilski", Blagoevgrad. 30 individuals were divided into two experimental groups. The first experimental group (EG-1) includes 15 athletes (2 women and 13 men), football players and basketball players, and the second experimental group (EG-2) - 15 non-athletes (6 women and 9 men), all with chronic lumbar pain. Anthropometric and functional studies were performed before and after the monthly physiotherapy. The empirical material was statistically processed. A variational analysis was conducted with the Prism 3 program. The statistical significance of differences in mean values was determined using the Wilcoxon and Mann Whitney criteria and the Freedman ANOVA (with Dunn's test) for more than two samples. Statistical software for data processing and graphical presentation of results we use GraphPadPrism 3.0.

\section{Methodology}

Goal: The study aims are to develop, approve and monitor the effectiveness of methods and algorithms for the application of specialized magnetotherapy with underwater water-jet massage for chronic lumbar pain.

Tasks: Achieving the goal requires accomplishing the following more important tasks:

1. Presentation of the study of the Research Ethics Committee of SWU “N. Rilski” (study approved).

2. Determining the contingent and conducting preliminary studies to refine the studied groups (by age, gender, type of sport) and make schedules.

3. Signing of an informed consent statement.

4. Refined contingent needing to accelerate the recovery process in lumbar pain, through hydrotherapy procedures.

5. Investigating the capabilities of the tangent systems to achieve the above effects.

6. Development of a program of targeted impact for patients with chronic pain in the lumbar region and the application of a specialized magnetotherapy with an underwater water-jet massage.

7. Capture baseline of the studied indicators of patients with chronic lumbar pain.

8. Performing procedures with a specialized magnetotherapy with an underwater water-jet massage.

9. Capture the final results of the studied indicators (after the last procedure).

10. Data processing and analysis of results.

Scientific and methodological approaches:

1. Organization of the study contingent.

2. Conducting experimental studies (anthropometric measurements, functional studies of the target groups).

3. Statistical analysis of the results.

- Variational analysis.

- Alternative analysis.

The empirical material collected was processed with the Prism3 statistical package.

\section{Methodology of Physiotherapy}

Goal: Establishing the effectiveness of physiotherapy with a specialized magnetotherapy with underwater water-jet massage to accelerate the recovery process in athletes and non-athletes with chronic lumbar pain.

Tasks:

1. Analytical impact of neurological and pain symptoms.

2. Reduction of paravertebral muscle spasm.

3. Restoration of the neurodynamics of n.ischiadicus.

4. Improvement of the volume of movement in the lumbar region of the spine and in the hip joints.

Functional study: The study is conducted by one experimenter.

- Anthropometry (height, weight).

- Visual Analog Pain Scale.

- Laseg test - for the neurodynamics of n.ischiadicus.

The test battery is applied before and after one month of physiotherapy.

Means: specialized tangentor with magnetotherapy and hydro massage. Procedures are applied according to schedule within 30-35 minutes. Hydrotherapy: water temperature $-36^{\circ}-37^{\circ}$. The underwater 24 jets are applied at the beginning and end of the procedure, lasting 5 minutes each, as a preparatory and final part, affecting the whole body. The water pressure of the hydromassage (tangent massage nozzle) increases gradually from 0.5 to 2 atmospheres. The angle of action between the water jet and the body starts from $15^{\circ}-20^{\circ}$ and gradually rises without causing pain and discomfort. It treats paravertebral musculature in the lumbar region, gluteus and lower limbs - dorsally and ventrally. Magnetotherapy: 15 min duration, administered concurrently with hydrotherapy. The program is automated and includes: $3.45 \mathrm{~min}$ - $25 \mathrm{~Hz}$ - rectangular bipolar, $3.45 \mathrm{~min}-6$ $\mathrm{Hz}$ - rectangular bipolar, $3.45 \mathrm{~min}-25 \mathrm{~Hz}$ - sinus bipolar, $3.45 \mathrm{~min}-6 \mathrm{~Hz}$ - sinus bipolar. The procedures are applied 3 times a week for one month. Or a total of 12 procedures. Procedures are avoided in the evening as stimulation of the body leads to sleep disturbance and has a diuretic effect.

Indications for the application of hydrotherapy:

- Pain in the lumbosacral area

- Pain in the course of the n.ischiadicus

- Paravertebral muscle spasm

- Limited range of motion in the lumbar region of the spine

- Lower limb symptoms, etc.

Contraindications for hydrotherapy and magnetotherapy:

- Acute phase of neurological symptoms

- Deterioration of neurological signs

- Acute inflammatory processes, fever, tumors disorders

- Heart failure, myocardial disorders, heart rhythm

- Epilepsy, seizures

- Hypotonic and hypertensive crises

- Pregnancy

- Thrombosis, bleeding

- Infectious 


\section{RESULTS AND ANALYSIS.}

The mean age of the first experimental group (EG1) was $\bar{X}=22.27 \pm 5.52$ years, at V\% $=24.80 \%$. Their average height was $\bar{X}=176.4 \pm 8.78 \mathrm{~cm}$., at $\mathrm{V} \%=4.97 \%$, and body weight $\bar{X}=71.33 \pm 12.75 \mathrm{~kg}$., at V\% $=17.87 \%$.

The mean age of the second experimental group (EG-2) was $\bar{X}=51.27 \pm 2.82$ years, at V\% $=21.28 \%$. Their average height was $\bar{X}=171.7 \pm 7.85 \mathrm{~cm}$, at V\% $=4.57 \%$ and body weight $\bar{X}=85.73 \pm 3.97 \mathrm{~kg}$., at V\% $=17.96 \%$.

The results of the investigated pain on the visualanalogue scale of the EG-1 athletes - before the application of physiotherapy (with hydrotherapy) show mean values $\bar{X}=4.93 \pm 1.39 \mathrm{~mm}$, at $\mathrm{V} \%=28.12 \%$, which indicates the presence of severe pain in the lumbar region. After 30 days of physiotherapy, it was reduced to $\bar{X}=1.53 \pm 0.99 \mathrm{~mm}$, at $\mathrm{V} \%=64.59 \%$. As a result, the reduction after therapy was $31.03 \%$.

P-values are below $0.05(\mathrm{P}<0.01)$ and indicate that the applied physiotherapy model has led to statistically significant positive changes in the studied indicator in EG-1 (Fig. 1).

Fig. 1. VAS - Visual Analogue Scale of pain EG-1

\section{EG-1}

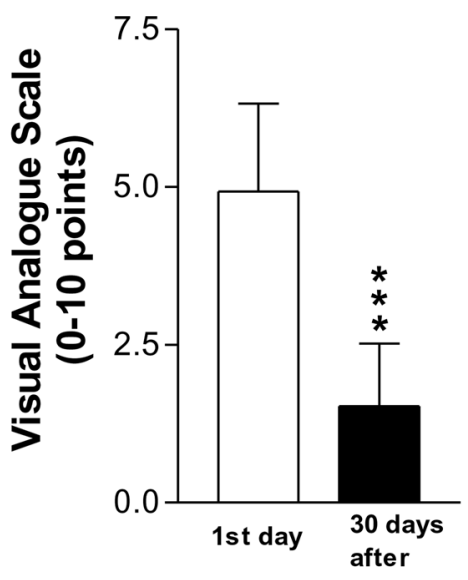

In the second experimental group EG-2 (Fig. 2), the mean pain value of VAS before physiotherapy $\bar{X}=6.87 \pm$ $1.64 \mathrm{~mm}$, at $\mathrm{V} \%=23.91 \%$ was found. After 30 days, physiotherapy was reduced to $\bar{X}=1.93 \pm 1.49 \mathrm{~mm}$, at V\% $=76.89 \%$.

$\mathrm{P}<0.01$ and its values indicate that the applied model of physiotherapy led to statistically significant positive changes of the studied indicator in the second experimental group EG-2 of the non-trained persons.
Fig. 2. VAS - Visual Analogue Scale of pain EG-2

\section{EG-2}

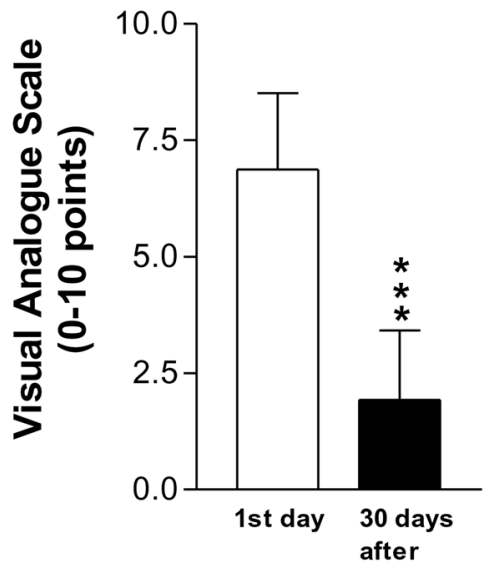

From the study of neurodynamics of n.ischiadicus, through the Laseg test, the patients of EG-1 (Fig. 1) found that the averages of passive flexion in the hip joint of their healthy leg before physiotherapy EG-1 $\bar{X}=76.33 \pm 8.76^{\circ}$, at a variety of results of $\mathrm{V}=11.47 \%$.

After 30 days of hydrotherapy, the passive flexion in the hip joint of their healthy leg increased to $\bar{X}=86.33 \pm$ $5.51^{\circ}$, at low values of $\mathrm{V} \%=6.37 \%$.

In the experimental group of athletes, passive flexion was found in the hip joint of the injured leg, before hydrotherapy $\bar{X}=69.67 \pm 10.43^{\circ}$, which indicates its strong limitation. The coefficient of variation V\% $=14.67 \%$ is not high and shows the relative homogeneity of the tested athletes with respect to their passive flexion. After 30 days of physiotherapy, her mean values reach $\bar{X}=80.33 \pm 10.08^{\circ}$, at V\% $=12.55 \%$.

$\mathrm{P}<0.01$, which implies that the applied physiotherapy model led to statistically significant positive changes in the passive flexion of the injured leg, of the EG-1 athletes, after hydrotherapy and physiotherapy.

Fig. 3. Laseg test EG-1

\section{EG-1}

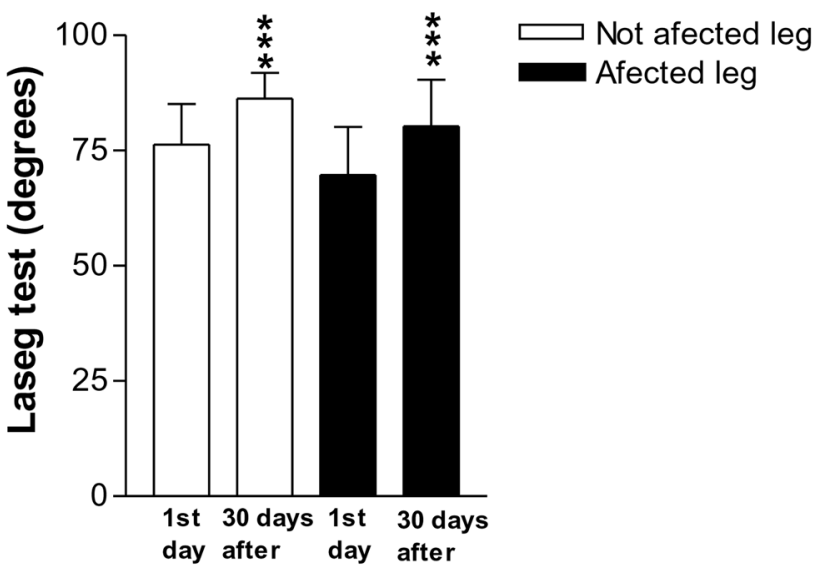


Regarding the non-athletes in the experimental group EG-2 (Fig. 4), the results show that the average values of passive flexion in the hip joint, before the physiotherapy of their healthy leg $\bar{X}=71.67 \pm 14.1^{\circ}$, at V\% $=19.67 \%$. After 30 days of targeted hydrotherapy, it increased $\bar{X}=81.53 \pm$ $8.37^{\circ}, \mathrm{V} \%=10.26 \%$.

In the injured leg, passive flexion - before hydrotherapy is $\bar{X}=71.00 \pm 11.37^{\circ}$, which indicates its strong limitation. $\mathrm{V} \%=16.01 \%$.

After hydrotherapy and physiotherapy, the index improved to $\bar{X}=82.07 \pm 7.70^{\circ}$, at V\% $=9.39 \%$.

$\mathrm{P}$-values are below $0.05(\mathrm{P}<0.01)$, which indicates that the applied physiotherapy model (with hydrotherapy according to the experimental model) resulted in statistically significant improvements of the studied indicator in non- trainees EG-2 thus establishing the efficacy of the tools, methods and approaches applied.

Fig. 4. Laseg test EG-2

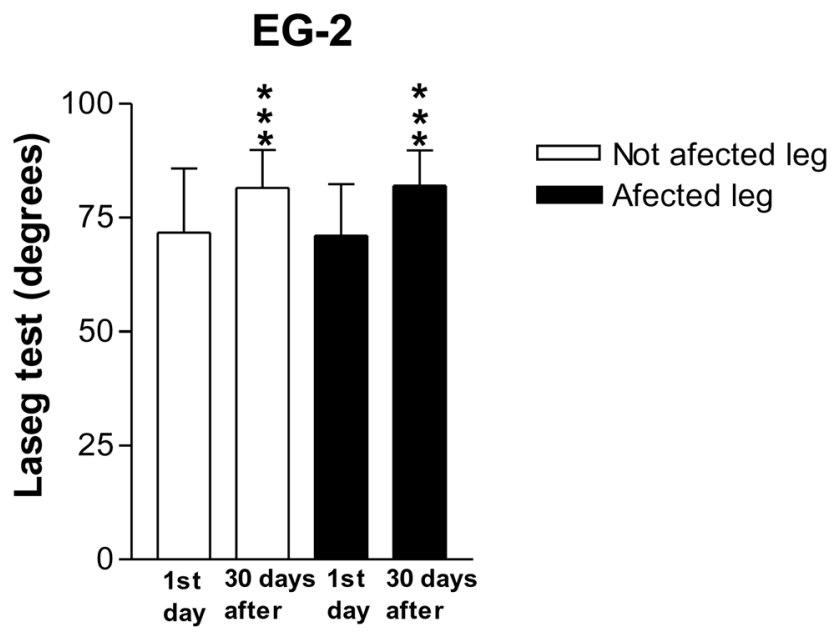

\section{DISCUSSION}

The methodology developed and tested using a specialized magnetotherapy with underwater water-jet massage for patients with chronic lumbar pain in athletes and nonathletes leads to statistically significant improvements in the studied parameters. Reduces pain, improves the neurodynamics of n.ischiadicus, increases the volume of movement in the hip joints, decreases the hypertonus of the paravertebral muscles in the lumbar region in both study groups.

The positive effects of warm underwater massage on neuromuscular function and muscle pain have been studied $[6,12]$.

\section{CONCLUSION}

The proven technique and algorithms of hydrotherapy, with a specialized tangentor, with magnetotherapy, is effective for the recovery of persons with chronic lumbar pain. The technique reduces the neurological and pain symptoms and the restoration of n.ischiadicus.

\section{Acknowledgements:}

This article is supported under Project No. RP-A7/ 18. The topic of the project: Post-traumatic recovery of athletes with specialized tangentor and study of training load with biochemical methods.

\section{REFERENCES:}

1. Allegri M, Montella S, Salici F, Valente A, Marchesini M, Compagnone $\mathrm{C}$, et al. Mechanisms of low back pain: a guide for diagnosis and therapy. F1000Res. 2016 Jun 28;5:F1000 Faculty Rev-1530. [PubMed] [Crossref]

2. Muller-Schwefe G, Morlion B, Ahlbeck K, Alon E, Coaccioli S, Coluzzi F, et al. Treatment for chronic low back pain: the focus should change to multimodal management that reflects the underlying pain mechanisms. Curr Med Res Opin. 2017 Jul;33(7):1199-1210. [PubMed]

3. Bleakley C, McDonough S, Gardner E, Baxter GD, Hopkins JT, Davison GW. Cold-water immersion (cryotherapy) for preventing and treat- ing musclesoreness after exercise. Cochrane Database Syst Rev. 2012Feb; 15(2):CD008262. [PubMed]

4. Bender T, Karagulle Z, Balint GP, Gutenbrunner C, Balint PV, Sukenik S. Hydrotherapy, balneotherapy, and spa treatment in pain management. Rheumatol Int. 2005 Apr;25(3):220-4. [PubMed]

5. Hanzel A, Horvat K, Molics B, Berenyi K, Nemeth B, Szendi K, et al. Clinical improvement of patients with osteoarthritis using thermal mineral water at Szigetvar Spa-resultsof a randomised double-blind controlled study. Int J Biometeorol. 2018 Feb;62(2):253-259. [PubMed]

6. Viitasalo JT, Niemela K, Kaappola R, Korjus T, Levola M,
Mononen HV, et al. Warm underwater water-jet massage improves recovery from intense physical exercise. Eur J Appl Physiol Occup Physiol. 1995; 71(5):431-8. [PubMed]

7. Versey NG, Halson SL, Dawson BT. Effect of contrast water therapy duration on recovery of running performance. Int J Sports Physiol Perform. 2012 Jun;7(2):130-40. [PubMed]

8. Nemcic T, Budisin V, VrabecMatkovic D, Grazio S. Comparison of the effects of land-based and waterbased therapeutic exercises on the range of motion and physical disability in patients with chronic low-back pain: single-blinded randomized study. Acta Clin Croat. 2013 Sep; 52(3):321-7. [PubMed] 
9. Gramatikova M. Aquatherapy after reconstruction of the anterior cruciate ligament of knee joint. Activities in Physical Education and Sport. 2015; 5(1):33-36.

10. Gramatikova M, Mitova St, Popova D. Changes in the support stability indicators after arthroscopic knee intervention. Research in Kine- siology. 2015; 43(1):28-32.

11. Herrera E, Sandoval MC, Camargo DM, Salvini TF. Motor and sensory nerve conduction are affected differently by ice pack, ice massage, and cold water immersion. Phys Ther. 2010 Apr;90(4):581-91. [PubMed]

12. Konrad K, Tatrai T, Hunka A, Vereckei E, Korondi I. Controlled trial of balneo therapy in treatment of lowback pain. Ann Rheum Dis. 1992 Jun;51(6):820-2. [PubMed]

13. Morton RH. Contrast water immersion hastensplasmalactatede crease after intense aerobic exercise. $J \mathrm{Sci}$ Med Sport. 2007 Dec;10(6):467-70. [PubMed].

Please cite this article as: Gramatikova M, Mitova S, Valchev N. Effect of hydrotherapy on chronic pain in the lumbar region. J of IMAB. 2020 Oct-Dec;26(4):3485-3489. DOI: https://doi.org/10.5272/jimab.2020264.3485

Received: 24/09/2019; Published online: 21/12/2020

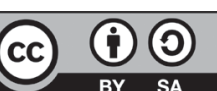

Address for correspondence:

Assoc. Prof. Mariya Gramatikova, PhD

Department of Kinesitherapy, Faculty of Public Health, Healthcare and Sports, South-West University "Neofit Rilski"

66. Ivan Mihaylov Str., 2700 Blagoevgrad, Bulgaria

E-mail: mari_gramatikova@abv.bg 